\title{
Comparative Study of Removal of Hexavalent Chromium from Water Using Metal Oxide Nanoparticles
}

\author{
V. N. Bhusari' ${ }^{1}$ Rashmi Dahake², Sadhana Rayalu², Amit Bansiwal2* \\ ${ }^{1}$ G.H. Raisoni College of Engineering, Nagpur, India \\ ${ }^{2}$ Environmental Materials Division, National Environmental Engineering Research Institute, CSIR (NEERI), \\ Nagpur, India \\ Email: "ak_bansiwal@neeri.res.in
}

Received 28 December 2015; accepted 13 February 2016; published 16 February 2016

Copyright (C) 2016 by authors and Scientific Research Publishing Inc.

This work is licensed under the Creative Commons Attribution International License (CC BY).

http://creativecommons.org/licenses/by/4.0/

(c) (i) Open Access

\begin{abstract}
Hexavalent chromium is one of the important heavy metals found in water and wastewater. The hexavalent form of chromium is considered to be a human carcinogen because of its mutagenic and carcinogenic properties. This work has focused on the comparison of copper oxide nanoparticles and aluminium oxide nanoparticles for the removal of chromium(VI) from water. The cooper oxide nanoparticles (CuNP) and aluminium oxide nanoparticles (AINP) were synthesised by sol gel method. Both the adsorbents were evaluated for the adsorption capacity using Langmuir and Freundlich adsorption model. The CuNP and AlNP were characterized for X-ray diffraction and SEM. The study indicated that the AINP showed better removal as compared to CuNP and can be further explored as potential adsorbent for hexavalent chromium removal.
\end{abstract}

\section{Keywords}

Adsorption, Chromium Removal, Metal Oxide, Nanoparticles

\section{Introduction}

Chromium is widely used by many industries and released into environment through various industrial processes including metal finishing industry, iron and steel industries and inorganic chemicals production, tanneries etc. High concentration of chromium in water may cause hazard to the environment [1]. Hexavalent chromium and its compounds are highly toxic and are considered as a carcinogen and mutagens [2]. The other effects of chro-

${ }^{*}$ Corresponding author.

How to cite this paper: Bhusari, V.N., Dahake, R., Rayalu, S. and Bansiwal, A. (2016) Comparative Study of Removal of Hexavalent Chromium from Water Using Metal Oxide Nanoparticles. Advances in Nanoparticles, 5, 67-74.

http://dx.doi.org/10.4236/anp.2016.51008 
mium(VI) on human health include lung cancer, liver, kidney and gastric damage, and epidermal irritation and sensitization [3]. Most surface water contains 1 to $10 \mu \mathrm{g} /$ liter of hexavalent chromium. The current guideline as per WHO value is $0.05 \mathrm{mg} /$ liter (WHO/SDE/WSH/03.04/04).

Various treatments employed for the removal of chromium from water include reduction, precipitation, ionexchange and solvent extraction etc. However, these methods are ineffective and require high energy for operation. Adsorption is considered as the most effective and widely used technique due to high removal efficiency, simplicity and low cost [4].

Many adsorbents have been reported for the removal of hexavalent chromium from water such as activated carbon (AC) [5] [6], activated alumina [7], chitosan polymer [8], zeolite [9], low cost bio-adsorbent such as olive, leaves, wool etc. [10], saw dust [11], rice husk, wheat bran [12], bentonite [13], metal oxides such as ferric hydroxide, Fe [14] ion exchange resin [15], nanostructured adsorbents [16] etc. Most of the adsorbents have low adsorption capacity and poor stability. The nature of adsorbent is mainly responsible for the chromium removal from water.

Nanoporous and nanostructured materials have unique surface area, structural and bulk properties. Because of these properties nanomaterials have important applications in environmental remediation and water purification. The most commonly used nanoparticles are nanoscale zero-valent iron which has also been reported for treatment of several wastewater contaminants including nutrients, organic pollutants, metals etc. The major limitation with existing nanopartcles is agglomeration and non-selectivity [17]. In this work different classes of adsorbents were synthesized and evaluated for chromium removal from water. Objective of the study was to synthesize copper oxide nanoparticles (CuNP) and aluminum oxide nanoparticles (AlNP) and compare them for removal of hexavalent chromium from water.

\section{Material and Method}

\subsection{Synthesis of Copper Oxide Nanoparticles (CuNP)}

All the chemicals used in this study were of analytical grade and procured from E-Merck India Ltd and Aldrich. The important chemicals used were copper nitrate, aluminium nitrate and monohydrate citric acid. Deionised water of highest purity was used throughout the study. CuNP was synthesised by taking $0.1 \mathrm{M}$ of Copper Nitrate used as a precursor solution and mono hydrated citric acid (Merck 99.5\%) as a gelating agent in appropriate amount of deionised water. The solution was then heated on hot plate and temperature was maintained to $85^{\circ} \mathrm{C}$ to $90^{\circ} \mathrm{C}$. The dried gel was calcined at temperatures of $500^{\circ} \mathrm{C}$ for $4 \mathrm{~h}$. The calcined material was again washed with DI water and oven dried for 3 - $4 \mathrm{~h}$. CuNP were prepared using different concentrations of copper nitrate and it was observed that $0.1 \mathrm{M}$ concentration of copper gave maximum removal efficiency and were selected for further studies.

\subsection{Aluminum Oxide Nanoparticles (AlNP)}

The same synthesis protocol was repeated as mentioned for the synthesis of CuNP except for using Aluminum Nitrate salt as precursor instead of Copper Nitrate.

\subsection{Characterisation of CuNP and AlNP}

The CuNP and AlNP were thoroughly characterized to study the structure, morphology and composition of CuNP and AINP by using techniques such as XRD, FTIR and TEM etc. The X-ray diffractometer (Model Rigaku: Miniflex) was used for identification of phases and crystalline species of CuNP and AlNP. The powdered sample was scan for $2 \theta$ ranges from $10^{\circ}$ to $90^{\circ}$. Transmission electron microscopy (TEM) analysis was carried out by JEOL instrument TEM Microscope (JSM 100 CX). Fourier transform infrared spectrometer (Bruker, Model Vertex) was used to determine the interaction of $\mathrm{Cr}$ with adsorbent.

\subsection{Adsorption Studies}

Initial solution of $5 \mathrm{mg} / \mathrm{L}$ of $\mathrm{Cr}(\mathrm{VI})$ was prepared from $1000 \mathrm{mg} / \mathrm{L}$ of chromium(VI) stock solution. In batch adsorption process 1 to $10 \mathrm{~g} / \mathrm{L}$ dose of adsorbent were taken in $250 \mathrm{ml}$ polycarbonate conical flasks. The flasks were kept in the orbital shaking incubator for 24 hours @ $150 \mathrm{rpm}$ at $27^{\circ} \mathrm{C} \pm 1^{\circ} \mathrm{C}$. The $\mathrm{pH}$ of sample was main- 
tained 6.5. After 24 hours shaking time the flask were withdrawn from the shaker and the adsorbent was separated by centrifugation and the supernatant was used for analysis of residual $\mathrm{Cr}(\mathrm{VI})$ concentrations using ICPMS (Perkin Elmer, Nexion 300). The NIST standards supplied by Sigma-Aldrich were used for calibration. The experiments were repeated twice and it was observed that the experimental error was within $\pm 2 \%$.

The amount of $\mathrm{Cr}(\mathrm{VI})$ adsorbed $\left(\mathrm{mg} \cdot \mathrm{g}^{-1}\right)$ at time $t$ was computed using following equation [18]:

$$
q_{t}=\frac{\left[C_{0}-C_{t}\right] V}{m}
$$

where, $C_{0}$ is the initial concentration of $\mathrm{Cr}(\mathrm{VI}), C_{t}$ is the concentration of $\mathrm{Cr}(\mathrm{VI})$ after adsorption at time $t, V$ is the volume of solution used and $m$ is the mass of adsorbent.

\section{Discussion}

\subsection{Characterization of Adsorbent}

The PXRD patterns of CuNP and AlNP are presented in Figure 1(a) and Figure 1(b). The sharp peaks obtained in Figure 1(a) at $2 \theta=35.46^{\circ}$ and $38.66^{\circ}$ shows crystalline nature of the CuNP and confirm the formation of CuO (PDF 89-2529) phases. The PXRD pattern of AlNP shown in Figure 1(b) revealed the amorphous nature of AlNP and no sharp peak was obtained. The broad peak observed between $20^{\circ}$ to $30^{\circ}$ may be assigned to $\mathrm{Al}_{2} \mathrm{O}_{3}$ phase.

Transmission Electron Microscopy (TEM) was carried out to determine the size and morphology of synthesized nanoparticles. The diameter of particles shows that most of the particles are below $100 \mathrm{~nm}$, however the accurate shape and size of particles could not be determined as the particles are agglomerated. High resolution image of AlNP (Figure 2(a)) shows nano-crystalline core coated with amorphous $\mathrm{Al}_{2} \mathrm{O}_{3}$. In $20 \mathrm{~nm}$ magnification the nanoparticles (Figure 2(b)) are clearly visible. The average diameter of the particles is about 20 to 50 $\mathrm{nm}$ and most of the particles are seen as aggregates. The SAED ring pattern in Figure 2(c) is indicated the amorphous nature of AlNP.

The TEM of CuNP is presented in Figure 3(a) and Figure 3(b). High resolution image of CuNP Figure 3(a) shows the particles aggregate on porous surface. The size and shape of particle depicted in Figure 3(b) confirms the particle size of about 30 to $60 \mathrm{~nm}$ and are nodular in shape. The SEAD pattern of CuNP shown in Figure 3(c) is dotted structure which confirms the crystalline nature of material.

The FTIR spectra of CuNP and AINP were obtained in the range of $400-4000 \mathrm{~cm}^{-1}$ with a resolution of 1 $\mathrm{cm}^{-1}$ presented in Figure 4(a) and Figure 4(b). In order to identify possible interaction and functional groups present on the surface of CuNP and AlNP FTIR studies were performed. FTIR studies were performed before and after $\mathrm{Cr}(\mathrm{VI})$ adsorption on CuNP and AlNP. The FTIR spectrum of CuNP show some major peaks at 1019, 1593, $1735 \mathrm{~cm}^{-1}$. The band corresponds to the 1513, 1539 and 1735 observed in CuNP and AlNP which normally of metal bonding. The peaks obtained at 3716 to 3798 in CuNP and AlNP is attributed due to OH stretching vibration.

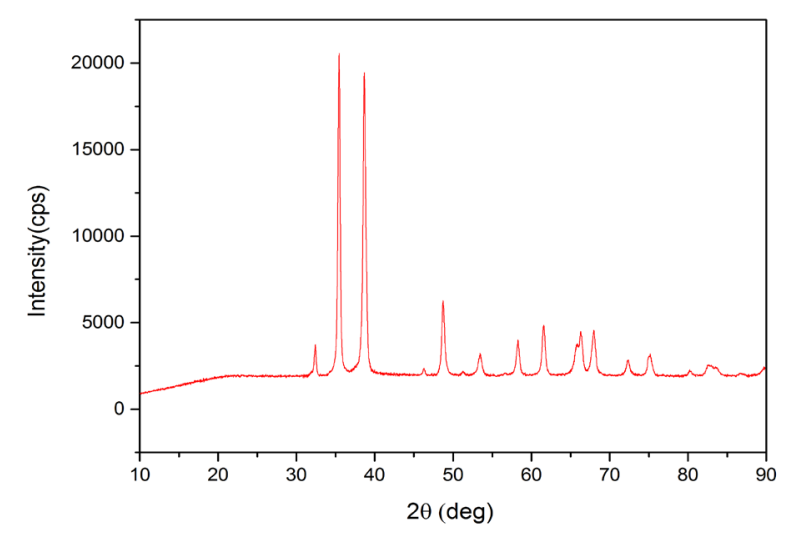

(a)

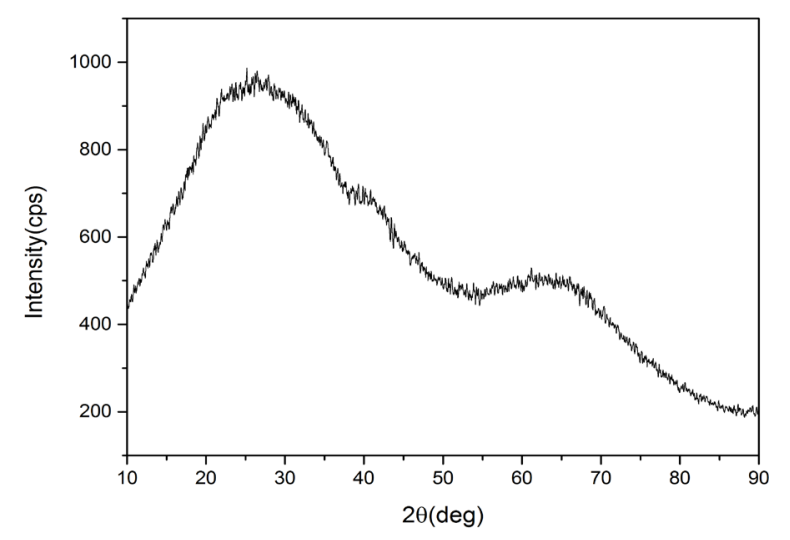

(b)

Figure 1. (a) XRD of CuNP; (b) XRD of AINP. 


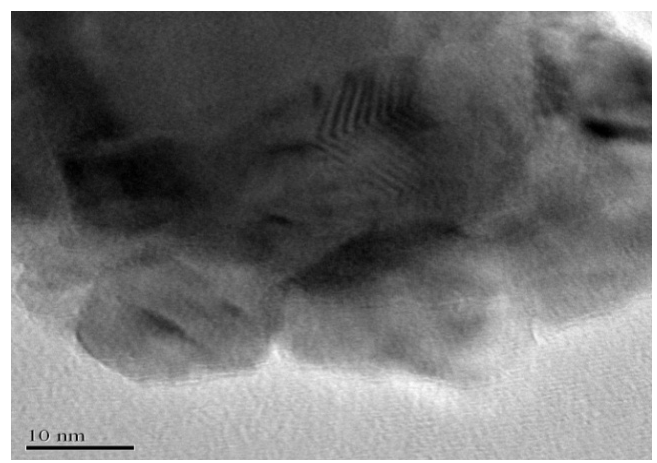

(a)

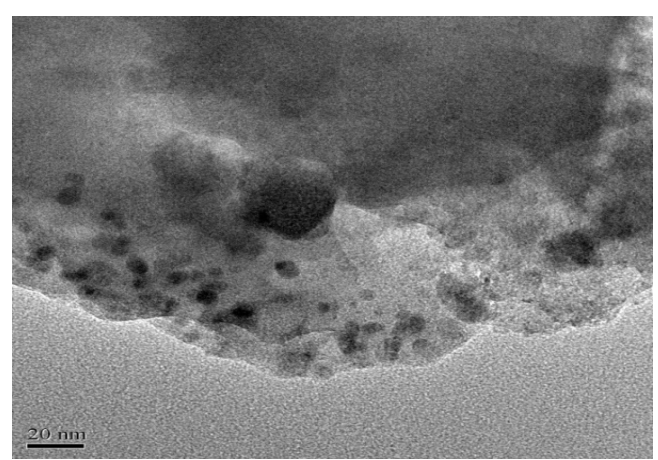

(b)

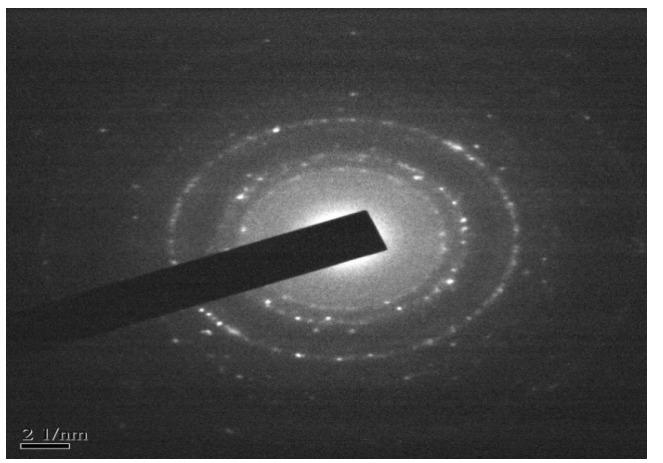

(c)

Figure 2. TEM of AINP.

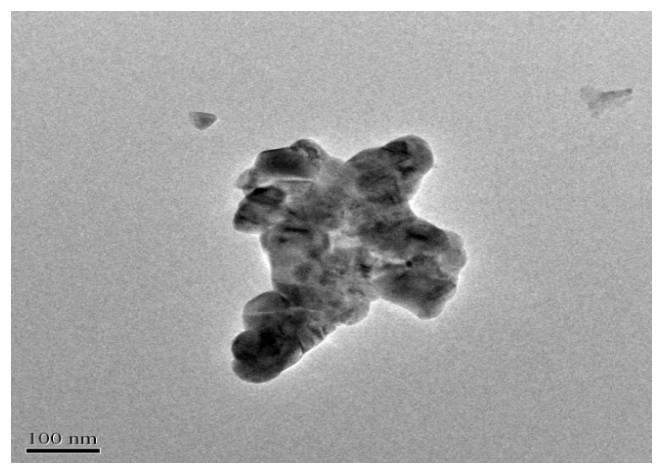

(a)

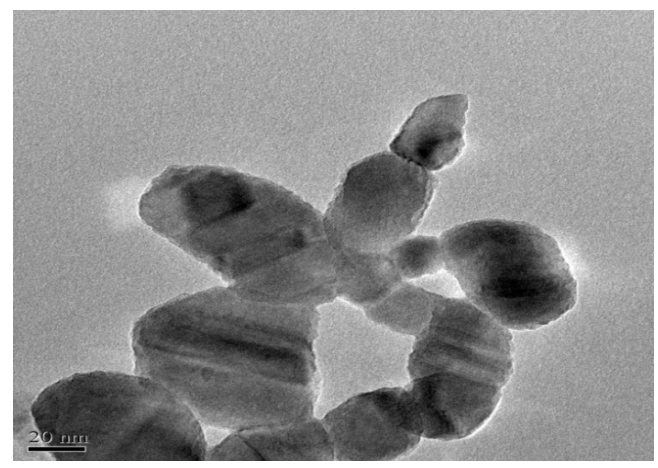

(b)

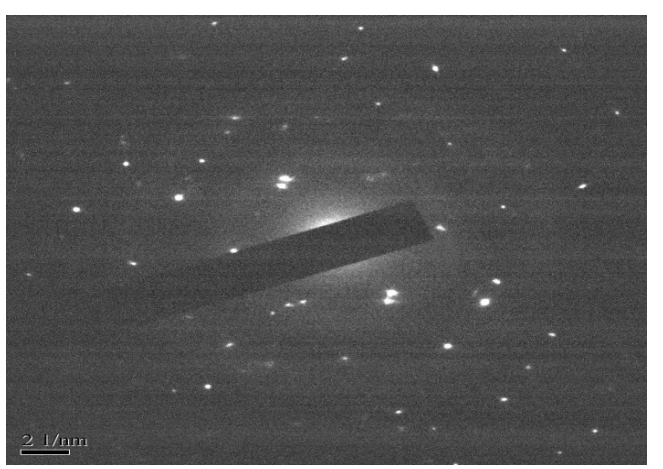

(c)

Figure 3. TEM of CuNP. 


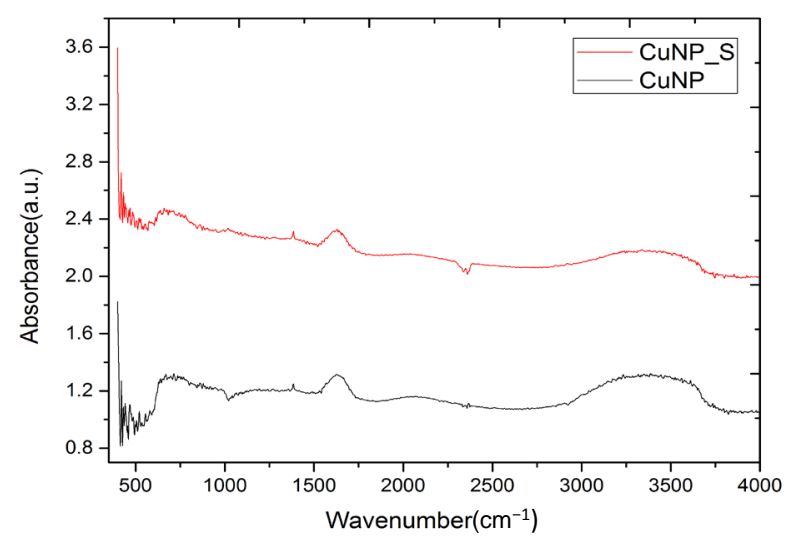

(a)

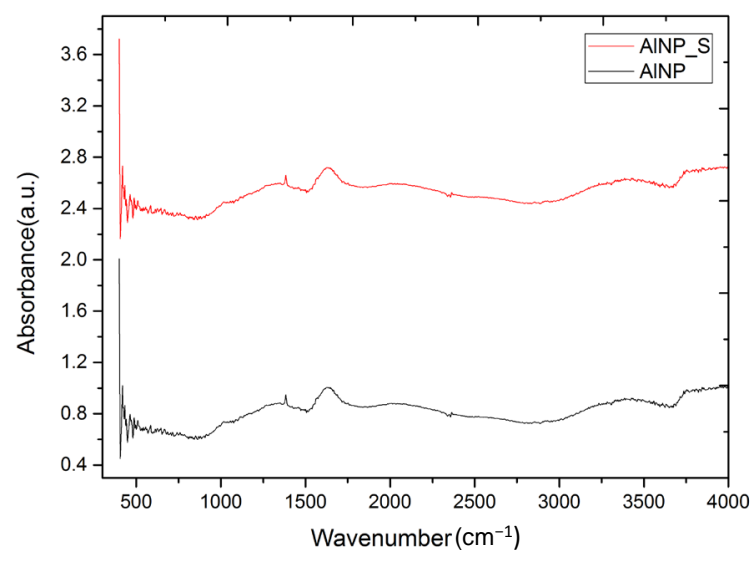

(b)

\section{Figure 4. (a) FTIR of CuNP; (b) FTIR of AINP.}

\subsection{Batch Adsorption Study}

\section{Effect of Adsorbent Dose}

The batch adsorption study of CuNP and AlNP were carried out to see the maximum adsorption at optimum dose with respect to contact time. The initial concentration of $\mathrm{Cr}(\mathrm{VI})$ was used $5 \mathrm{mg} / \mathrm{l}$ and $\mathrm{pH}$ was maintained 6.5. It was observed that the removal efficiency of AlNP was $98.3 \%$ at adsorbent dose of $10 \mathrm{~g} / \mathrm{L}$ as compared to CuNP which exhibit $60 \%$ removal at same dose. The effect of adsorbent dose on adsorption efficiency of both adsorbent is shown in Figure 5.

\section{Results}

\section{Adsorption Isotherms}

In order to study the adsorption behaviour and to calculate adsorption capacity, Langmuir and Freundlich adsorption models were used. Langmuir isotherm model is most widely used isotherm applicable to monolayer adsorption on identical sites [19]. The Langmuir adsorption model can be represented in linear form as follows.

$$
\frac{1}{q_{e}}=\frac{1}{q_{m} K_{L} C_{e}}+\frac{1}{q_{m}}
$$

The adsorption capacity $Q_{\max }$ and energy of adsorption $(k)$ were calculated from the slope and intercept of the Langmuir plot and found to be $1.93 \mathrm{mg} / \mathrm{g}$ for AlNP. Similarly the adsorption capacity obtained for CuNP was $19.61 \mathrm{mg} / \mathrm{g}$.

The Freundlich model indicates heterogeneous adsorption on the adsorbent surface and considers as a multilayer adsorption. It is given by equation [20].

$$
\log \left(q_{e}\right)=\log _{k}+\frac{1}{n} \log \left(C_{e}\right)
$$

where $q_{e}$ is the adsorption capacity and $n$ is the Freundlich constant related to adsorption intensity, $C_{e}$ is the equilibrium concentration of adsorbate in solution $\left(\mathrm{mg} \cdot \mathrm{l}^{-1}\right)$.

The experimental data and Langmuir and Freundlich adsorption isotherm fits for adsorption of $\mathrm{Cr}(\mathrm{VI})$ on AlNP and CuNP are presented in Figure 6(a) \& Figure 6(b) and Figure 6(c) \& Figure 6(d) respectively. The isotherm parameters are given in Table 1. On comparison of the fitness of the adsorption isotherm, Langmuir model is more appropriate for adsorption of $\mathrm{Cr}(\mathrm{VI})$ on AlNP.

\section{Conclusion}

The nanoparticles of CuNP and AlNP were synthesized and evaluated for removal of Cr(VI) from synthetic water. On comparison of the adsorption of $\mathrm{Cr}(\mathrm{VI})$ on copper oxide and aluminium oxide nanoparticles, it was 


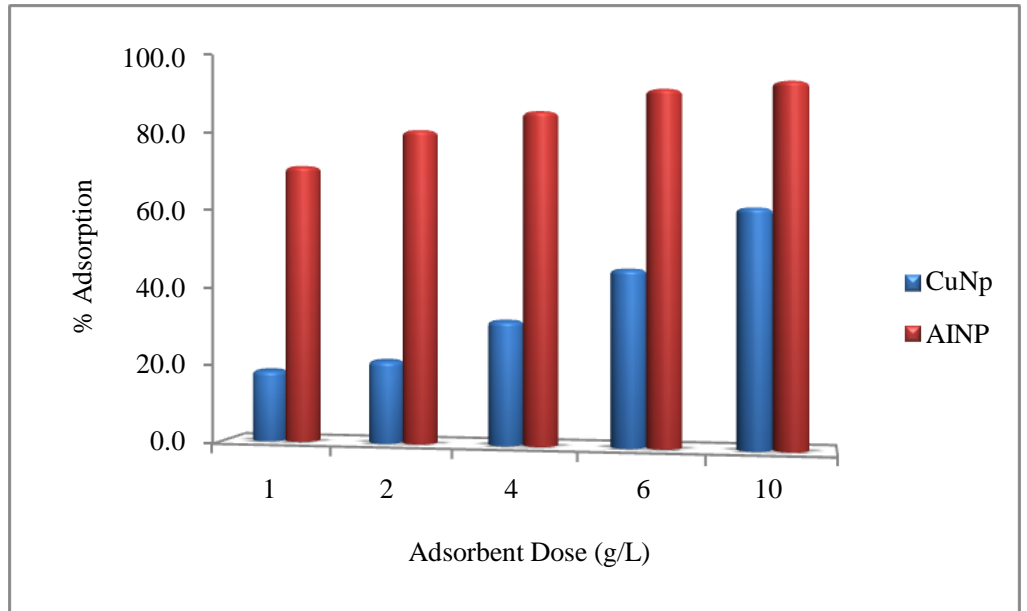

Figure 5. Adsorption of Cr(VI) on CuNP and AlNP.

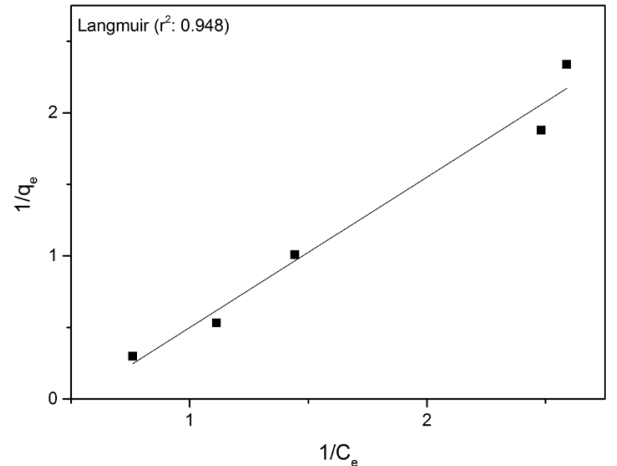

(a)

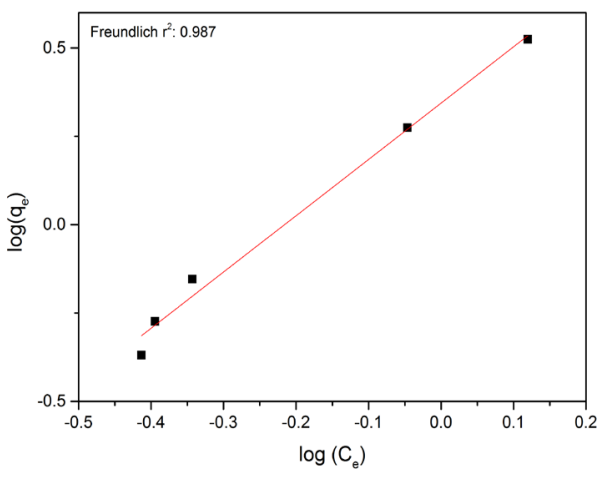

(c)

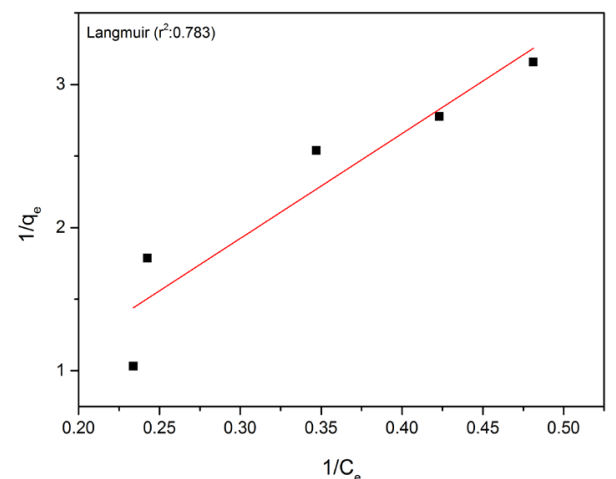

(b)

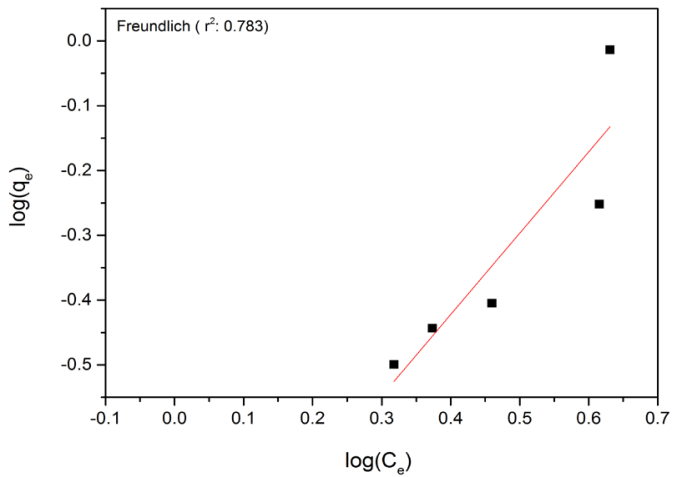

(d)

Figure 6. (a) Langmuir isotherm for AINP; (b) Langmuir isotherm of CuNP; (c) Freundlich isotherm for AlNP; (d) Freundlich isotherm for CuNP.

Table 1. Adsorption isotherm parameters for chromium adsorption on AlNP and CuNP.

\begin{tabular}{ccccccc}
\hline \multirow{2}{*}{ Adsorbent } & \multicolumn{3}{c}{ Langmuir parameters } & \multicolumn{3}{c}{ Freundlich parameters } \\
\cline { 2 - 7 } & $\mathrm{q}_{\mathrm{m}} \mathrm{mg} \cdot \mathrm{g}^{-1}$ & $\mathrm{~K}$ & $\mathrm{R}^{2}$ & $\mathrm{Q}_{\mathrm{f}} \mathrm{mg} \cdot \mathrm{g}^{-1}$ & $1 / \mathrm{n}$ & $\mathrm{R}^{2}$ \\
\hline AlNP & 1.93 & 0.52 & 0.948 & 1.276 & 1.359 & 0.843 \\
CuNP & 19.61 & 0.01 & 0.783 & 1.669 & 0.406 & 0.353 \\
\hline
\end{tabular}


observed that AlNP exhibit excellent efficiency for the removal of $\mathrm{Cr}(\mathrm{VI})$. The PXRD analysis confirms the synthesis and presence of aluminium oxide and copper oxide phases. TEM images of CuNP and AINP also confirm the formation of nanoparticles. The AlNP showed significantly high adsorption capacity for removal of $\mathrm{Cr}(\mathrm{VI})$ from water as compared to CuNP.

\section{References}

[1] Wu, Y., Zhang, S.Z., Guo, X.Y. and Huang, H.L. (2008) Adsorption of Chromium(III) on Lignin. Bioresource Technology, 99, 7709-7715. http://dx.doi.org/10.1016/j.biortech.2008.01.069

[2] Samaras, P., et al. (2009) Effect of Hexavalent Chromium on the Activated Sludge Process and on the Sludge Protozoan Community. Bioresource Technology, 100, 38-43. http://dx.doi.org/10.1016/j.biortech.2008.05.036

[3] Das, D.D., Mahapatra, R., Pradhan, J., Das, S.N. and Thakur, R.S. (2000) Removal of Cr(VI) from Aqueous Solution Using Activated Cow Dung Carbon. Journal of Colloid and Interface Science, 232, 235-240. http://dx.doi.org/10.1006/jcis.2000.7141

[4] Wu, X.-W., Ma, H.-W. and Zhang, Y.-R. (2010) Adsorption of Chromium(VI) from Aqueous Solution by a Mesoporous Aluminosilicate Synthesized from Microcline. Applied Clay Science, 48, 538-541. http://dx.doi.org/10.1016/j.clay.2010.02.013

[5] Mohan, D. and Pittman Jr., C.U. (2006) Activated Carbons and Low Cost Adsorbents for Remediation of Tri- and Hexavalent Chromium from Water. Journal of Hazardous Materials, B137, 762-811. http://dx.doi.org/10.1016/j.jhazmat.2006.06.060

[6] Valix, M., Cheung, W.H. and Zhang, K. (2006) Role of Heteroatoms in Activated Carbon for Removal of Hexavalent Chromium from Wastewaters. Journal of Hazardous Materials, 135, 395-405. http://dx.doi.org/10.1016/j.jhazmat.2005.11.077

[7] Mor, S., Ravindra, K. and Bishnoi, N.R. (2007) Adsorption of Chromium from Aqueous Solution by Activated Alumina and Activated Charcoal. Bioresource Technology, 98, 954-957. http://dx.doi.org/10.1016/j.biortech.2006.03.018

[8] Hena, S. (2010) Removal of Chromium Hexavalent Ion from Aqueous Solutions Using Biopolymer Chitosan Coated with Poly 3-Methyl Thiophene Polymer. Journal of Hazardous Materials, 181, 474-479. http://dx.doi.org/10.1016/j.jhazmat.2010.05.037

[9] Basaldella, E.I., Vázquez, P.G., Iucolano, F. and Caputo, D. (2007) Chromium Removal from Water Using LTA Zeolites: Effect of pH. Journal of Colloid and Interface Science, 313, 574-578. http://dx.doi.org/10.1016/j.jcis.2007.04.066

[10] Dakiky, M.U., Khamis, M., Manassra, A. and Mer’eb, M. (2002) Selective Adsorption of Chromium(VI) in Industrial Wastewater Using Low-Cost Abundantly Available Adsorbents. Advances in Environmental Research, 6, 533-540. http://dx.doi.org/10.1016/S1093-0191(01)00079-X

[11] Baral, S.S., Das, S.N. and Rath, P. (2006) Hexavalent Chromium Removal from Aqueous Solution by Adsorption on Treated Sawdust. Biochemical Engineering Journal, 31, 216-222. http://dx.doi.org/10.1016/j.bej.2006.08.003

[12] Singha, B., Naiya, T.K., Bhattacharya, A.K. and Das, S.K. (2011) Cr(VI) Ions Removal from Aqueous Solutions Using Natural Adsorbents-FTIR Studies. Journal of Environmental Protection, 2, 729-735. http://dx.doi.org/10.4236/jep.2011.26084

[13] Rashmi, O., Ramteke, D.S. and Meshram, P.U. (2012) Clay Intercalation Compound: Chromium Removal Study. International Journal of Research in Chemistry and Environment, 2, 83-87.

[14] Asagari, A.R., Vaezi, F., Nasseri, S., Dordelmann, O., Mahvi, A.H. and Deghani Fard, E. (2008) Removal of Hexavalent Chromium from Drinking Water by Granuler Ferric Hydroxide. Iranian Journal of Environmental Health Science \& Engineering, 5, 277-282.

[15] Rafati, L., Mahvi, A.H., Asgari, A.R. and Hosseini, S.S. (2010) Removal of Chromium (VI) from Aqueous Solutions Using Lewatit FO36 Nano Ion Exchange Resin. International Journal of Environmental Science \& Technology, 7, 147156. http://dx.doi.org/10.1007/BF03326126

[16] Huang, S.-H. and Chen, D.-H. (2009) Rapid Removal of Heavy Metal Cations and Anions from Aqueous Solutions by an Amino-Functionalized Magnetic Nano-Adsorbent. Journal of Hazardous Materials, 163, 174-179. http://dx.doi.org/10.1016/j.jhazmat.2008.06.075

[17] Liu, T.Y., Zhao, L., Sun, D.S. and Tan, X. (2010) Entrapment of Nanoscale Zero-Valent Iron in Chitosan Beads for Hexavalent Chromium Removal from Wastewater. Journal of Hazardous Materials, 184, 724-730. http://dx.doi.org/10.1016/j.jhazmat.2010.08.099

[18] Nameni, M., Alavi Moghadam, M.R. and Arami, M. (2008) Adsorption of Hexavalent Chromium from Aqueous Solutions by Wheat Bran. International Journal of Environmental Science \& Technology, 5, 161-168.

http://dx.doi.org/10.1007/BF03326009 
[19] Langmuir, I. (1916) The Constitution and Fundamental Properties of Solids and Liquids. Journal of the American Chemical Society, 38, 2221-2295. http://dx.doi.org/10.1021/ja02268a002

[20] Freundlich, H.M.F. (1906) Uber Die Adsorption in Losungen. Zeitschrift fur Physikalische Chemie (Leipzig), 57, 385470. 